\title{
A Comparison of Various Technological Options for Improving Energy and Water Use Efficiency in a Traditional Sugar Mill
}

\author{
Eyerusalem Birru ${ }^{1, *}$, Catharina Erlich ${ }^{1}$, Idalberto Herrera ${ }^{2}$, Andrew Martin ${ }^{1}$, Sofia Feychting ${ }^{3}$, \\ Marina Vitez ${ }^{3}$, Emma Bednarcik Abdulhadi ${ }^{3}$, Anna Larsson ${ }^{3}$, Emanuel Onoszko ${ }^{3}$, \\ Mattias Hallersbo ${ }^{3}$, Louise Weilenmann ${ }^{3}$ and Laura Puskoriute ${ }^{3}$ \\ 1 Department of Energy Technology, KTH Royal Institute of Technology, \\ School of Industrial Technology and Management (ITM), 10044 Stockholm, Sweden; \\ erlich.catharina@energy.kth.se (C.E.); andrew@energy.kth.se (A.M.) \\ 2 Center for Energy and Environmental Technologies Assessment (CEETA), \\ Faculty of Mechanical and Industrial Engineering Central, University “Marta Abreu” of Las Villas (UCLV), \\ 54830 Santa Clara, Cuba; iherrera@kth.se \\ 3 KTH Royal Institute of Technology, School of Industrial Technology and Management (ITM), \\ 10044 Stockholm, Sweden; sofiafe@kth.se (S.F.); vitez@kth.se (M.V.); emmabed@kth.se (E.B.A.); \\ annala8@kth.se (A.L.); eonoszko@kth.se (E.O.); hallersb@kth.se (M.H.); louiseny@kth.se (L.W.); \\ laurapu@kth.se (L.P.) \\ * Correspondence: birru@kth.se or eyerusalem.deresse.birru@energy.kth.se; Tel.: +46-8-790-7428 \\ Academic Editor: Alessandro Franco \\ Received: 31 August 2016; Accepted: 4 November 2016; Published: 25 November 2016
}

\begin{abstract}
This study is a comparison of four technological improvements proposed in previous works for the Cuban sugar mill Carlos Baliño. These technological options are: (1) utilization of excess wastewater for enhanced imbibition; (2) utilization of waste heat for thermally driven cooling; (3) utilization of excess bagasse for pellets; and (4) modification of the cogeneration unit for maximum electric power generation. The method used for the evaluation of the technological options involves using criteria such as energy saving, financial gains, and $\mathrm{CO}_{2}$ emission saving potential. The results of the analysis show that the first three technological improvement options are attractive only during the crushing season. On the other hand, the last technological improvement option can be attractive if a year round generation of surplus power is sought. The first technological improvement option leads to only minor changes in energy utilization, but the increase in sugar yield of $8.7 \%$ leads to attractive profitability with an extremely low payback period. The $\mathrm{CO}_{2}$ emissions saved due to the fourth technological improvement option are the highest (22,000 tonnes/year) and the cost of $\mathrm{CO}_{2}$ emissions saved for the third technological improvement option (lowest) amount to $41 \mathrm{USD} /$ tonne of $\mathrm{CO}_{2}$ emissions saved. The cycle efficiencies of the third and fourth technological improvement options are $37.9 \%$ and $36.8 \%$, respectively, with payback periods of 2.3 and 1.6 years. The second technological improvement option is the least attractive alternative of the group.
\end{abstract}

Keywords: sugar cane bagasse; Carlos Baliño; energy efficiency; wastewater reuse; imbibition; $\mathrm{CO}_{2}$ emission; absorption chiller; pellet; electricity; energy saving; payback period

\section{Introduction}

Global economic expansion and population growth have resulted in an increased demand of two valuable resources: energy and water. These two resources are interdependent in that water is a vital input for production of energy services, and energy is crucial for the provision of water [1]. Concern about the limited supply of these resources and climate change has led to measures such as energy 
efficiency improvements, use of renewable energy based technologies and water use optimization. Currently, such measures are being widely investigated and implemented in various industries worldwide. The sugar cane industry is one example where energy and water are both intensively used, and also wasted. Efficient utilization of these resources is crucial for maximizing the energy efficiency of sugar mills and for reducing emissions. Several studies have considered energy efficiency improvement measures by mainly focusing on maximization of electric power generation [2-5]. On the other hand, efficient utilization of water in sugar cane mills is not widely addressed compared to energy efficiency.

Efficient utilization of energy and water in the sugar cane industry is a key measure for tackling the problem of limited access to these resources in developing countries, where such industries are widely found. Cuba is one of these developing countries with sugar cane industries and struggling with limited access to renewable resource-based energy and water. The main source of energy in the Cuban energy supply is based on fossil fuels, and since 2005 there have been several energy efficiency improvement projects initiated by the government, which resulted in a decreased number of blackouts [6]. The sugar cane industry in Cuba can be one potential sector to implement energy efficiency measures with the aim of contributing to green electricity supply, reusing wastewater and utilizing the bagasse potential. The sugar mill Carlos Baliño has recently been upgraded, with electric drives replacing the old mechanical turbines and a new boiler. However, there was no upgrading of the turbines with subsequent efficiency improvement, so plenty of excess bagasse is currently being produced. Part of this bagasse is used as maintenance fuel as well as a sellable fuel for nearby sugar mills, yet a significant portion piles up as waste. Moreover, this mill retains an outdated approach to water treatment, as excess process water is simply led to ponds for evaporation.

In an attempt to address the above mentioned issues with the Carlos Baliño sugar mill, previous work had been done [7-10] where specific technological improvements were analyzed. These technological improvements, which were considered as part of field studies conducted during 2014 and 2015 [7-10], include the following: utilization of excess wastewater for enhanced imbibition; utilization of waste heat for thermally driven cooling; bagasse pelletization; and bagasse drying for surplus power generation. Parameters for analysis and comparison include energy performance, economic considerations, and $\mathrm{CO}_{2}$ emissions. The main objective of this study is to make a comparison of these technological improvements in water and energy utilization for the Carlos Baliño sugar mill, with the ultimate goal of assessing the most viable technologies among the alternatives.

\section{Background and Methods}

The case study plant, Carlos Baliño sugar mill, is located in Villa Clara, Cuba. It was built in 1903 and in 2001 it started producing ECOCERT-labeled organic sugar [11], which now accounts for $30 \%$ of its total sugar production. The sugar mill is known for its high efficiency equipment and high quality product. The cane crushing capacity is 2300 TCD (Tonne of cane per day) and the crushing season is between mid-December to April. The process steam pressure is 2.05 bar (abs.).

Figure 1 shows the process flow sheet for Carlos Baliño sugar mill. The process flow sheet indicates also the wastewater sinks and sources of the sugar mill (see $[7,8]$ for more information). The sugar production process is described in the following sub-sections. 


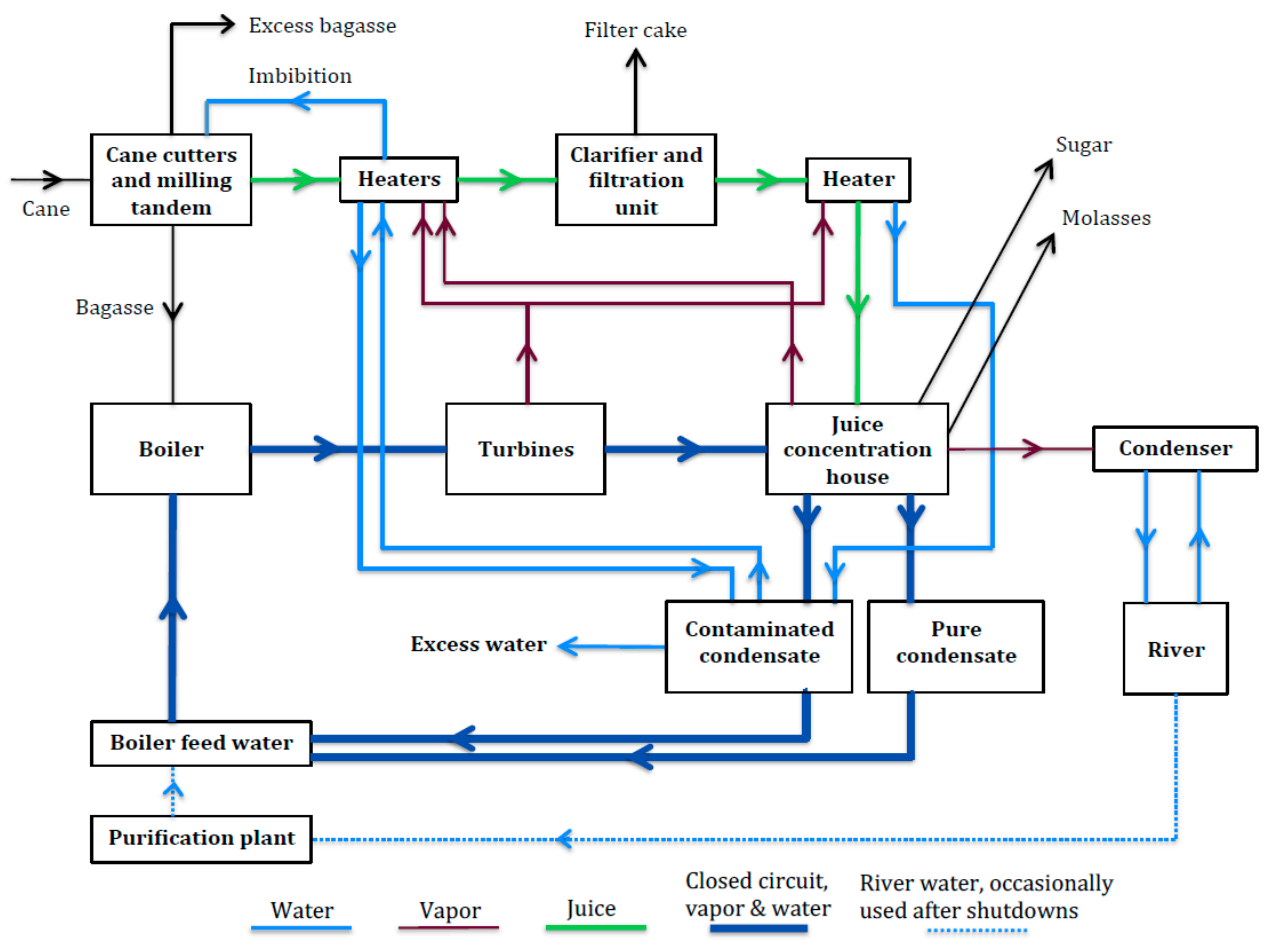

Figure 1. Flow sheet of Carlos Baliño sugar mill [8].

\subsection{Sugar Production Processing Steps at Carlos Baliño Sugar Mill}

In this section, the sugar production processes with some operation parameters are provided. All the information provided in this section is obtained (unless specified) from the documents collected during field visit to Carlos Baliño sugar mill.

\subsubsection{Cane Preparation}

The cane harvest is done beginning mid of December and lasts through out April each year [7]. The cane harvest uses mechanized harvest method. The transportation of the harvested cane to the cane cleaning unit is carried out using trucks and carts. The cane cultivation is done using organic agriculture methods. In the cleaning center, more than $50 \%$ of the foreign matter such as straw and soil is removed.

Clean cane is transported by trucks and unloaded to the cane feed conveyer where it is split and fed to the cane levelizer and subsequently rendered as cane sheets before reaching the cane knives. The cane knives are powered by two electric motors, 250 and $320 \mathrm{~kW}$ at $600 \mathrm{rpm}$ and $440 \mathrm{~V}$. The chopped cane is sent to the cane mill, comprised of a cane crusher and three roller mills driven by two electric motors ( $400 \mathrm{~kW}, 440 \mathrm{~V}$ and $600 \mathrm{rpm}$ ). Imbibition water at about $70{ }^{\circ} \mathrm{C}$ and a ratio of twice the fiber is added at the inlet of the third mill. Extracted juice from the second and third roller mills is recirculated to the adjacent mill. At this stage of the extraction process, besides sugar juice, bagasse is obtained and a part of the latter is sent to the boiler to generate electricity in addition to process steam. The other part of bagasse is intended for the production of compost and surplus for sale to other companies, with the remainder eventually landfilled.

\subsubsection{Juice Purification}

Next, the juice is heated in juice heaters to $105^{\circ} \mathrm{C}$ to promote reaction between milk of lime and phosphorous present in the juice. The juice then enters the clarifier where alkalizing and heating is done. The heated clear juice enters two rotary filters and two streams are produced: sludge/filter cake and the clarified filtered juice. This juice with $15^{\circ} \mathrm{Bx}$ is sent to the evaporators for juice concentration. 


\subsubsection{Juice Concentration}

The clear juice is fed to two pre-evaporators after heating it to $106-108^{\circ} \mathrm{C}$. These pre-evaporators operate in parallel receive exhaust steam with 15 Psi and produce juice with 8 Psi. The syrup leaves the evaporators with $60-63{ }^{\circ} \mathrm{Bx}$.

The syrup is then sent to the crystallization unit and centrifugation. Sugar coming out of the centrifuges usually has a moisture content of $0.5 \%-2 \%$. The sugar is dried using hot air to $42{ }^{\circ} \mathrm{C}$ and a reduced moisture content of $0.2 \%-0.5 \%$ may be achieved. Drying is usually carried out in a direct contact rotary drum dryer. This reduced moisture content of sugar is critical to prevent the growth of microorganisms and hardening that could cause damage in the stored product and improves handling. The separation of ferrous particles, which might come from cane handling and conveying equipment, is done by a self-cleaning magnetic separator located at the dryer outlet, resulting in 0 ppm Fe in the packaged sugar. The sugar is then sieved and packed.

\subsection{Cogeneration at Carlos Baliño Sugar Mill}

Steam is generated by combusting bagasse in suspension-type boiler with a temperature of $340-360{ }^{\circ} \mathrm{C}$ and a pressure of 18 bar. The boiler brand is RETAL, manufactured in Germany at the end of the eighties, converted into a CAP60 in 2008 in the steam boiler factory of Sagua la Grande, Cuba, originally designed to generate 45 tonnes $/ \mathrm{h}$. The boiler was converted to generate $60 \mathrm{ton} / \mathrm{h}$ steam at the same conditions of pressure and temperature. There are two back pressure steam turbines, manufactured in Germany in 1884, VEB Bergmann-Borsig brand, SG 49/3/6 model. These have an installed nominal capacity of $3.16 \mathrm{MW}$ and specific electricity provision of $32 \mathrm{kWh} / \mathrm{TC}$. Excess power is sent to the national grid [12]. The existing back pressure power turbines have a limitation in generating excess power more than the current amount [10]. The feed water pumps are KSB brand, series HGM and are manufactured in Germany.

The cogeneration unit of traditional sugar mills is commonly equipped with back pressure turbines for power generation, and the main focus is the production of electricity for the factory's consumption. Surplus power generation does not occur often, and only during the crushing season. The use of condensing extraction steam turbines however allows sugar mills to generate year round power generation [4]. During unplanned stoppages the cogeneration unit does not normally stop fully, rather the bagasse flow to the boiler will decrease, thus the boiler runs at a lower load. There are conditions where sugar mills use fuel oil during unplanned stoppages, incurring an extra cost and resulting in relatively high carbon dioxide emissions [13]. This is not the case in Carlos Baliño as the existing boilers can use only bagasse or wood. Thus, stored bagasse or purchased wood is used during unplanned stoppages as well as during boiler startups. On average, company records show that the factory operates at $70 \%$ of target capacity when including complete shutdowns in the statistics $[7,8]$.

\subsection{Technological Improvements under Consideration}

Four technological improvements as described in previous works [7-10] are discussed below.

\subsubsection{Option 1: Utilization of Excess Wastewater for Enhanced Imbibition}

Figure 2 illustrates the overall concept of Option 1, where the excess wastewater is recycled for imbibition (resulting in higher sugar production). The idea for re-using the excess waste water for imbibition as analyzed in the previous work [7] was proposed after it was determined that the existing imbibition water amount is not optimized and additional water is needed. As can be seen from Figure 1, a portion of contaminated condensate is mixed with the imbibition water supply, illustrating that excess wastewater has the potential to be recycled for imbibition without treatment. The imbibition water flow is such that there will be a maximum profit regarding the increased sugar production. It should be noted that there is an optimum amount of imbibition water needed for maximum sugar production. On the other hand, most sugar mills use imbibition water in excess which 
results only excess wastewater instead of increased sugar production. This is because the amount of sucrose extracted is not only a function of amount of imbibition water but also other factors such as hydraulic pressure of the roller mills, fiber content of cane, and the amount of cane mille. Thus, beyond a certain amount of imbibition water amount, there will not be sucrose extraction. The imbibition water optimization was done by varying the efficiency of the milling pair, which is the result of varied mass flow of imbibition water. This in turn results in variation in the amount of produced sugar. The optimum amount of imbibition water is thus the amount that results in maximum economic gain regarding sales of sugar. After identifying the optimum amount of imbibition water, which was estimated to be $11 \mathrm{~kg} / \mathrm{s}$ ( $96 \%$ increase from the currently used amount), part of the excess wastewater is reused and the remaining is sent to a wastewater treatment facility.

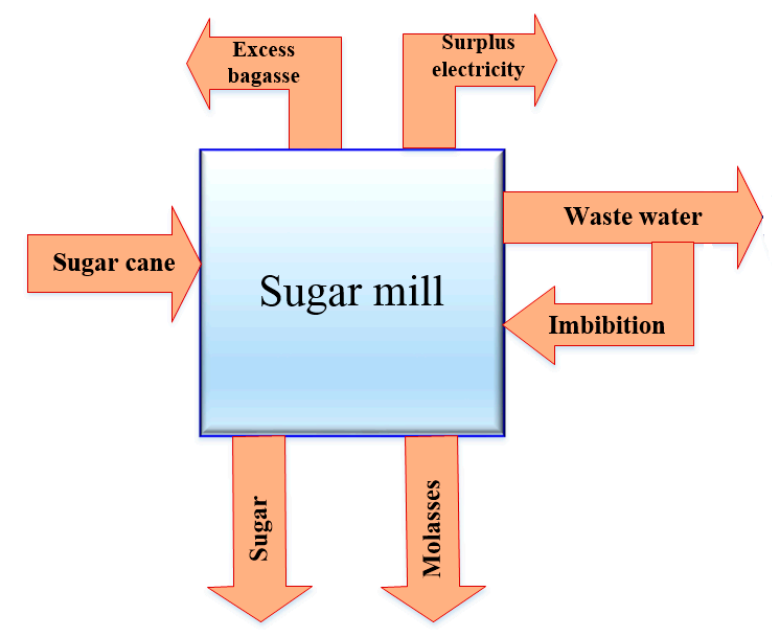

Figure 2. Wastewater for enhanced imbibition.

\subsubsection{Option 2: Utilization of Waste Heat for Thermally Driven Cooling}

The aim of the study was to analyze the possibilities of utilizing the waste heat in the excess wastewater flow as a heat source for a thermally driven absorption chiller in order to provide chilled water for air conditioning to laboratories and office areas of the mill. These facilities are currently air conditioned using electrically driven vapor compression air conditioning units. In this way the internal electricity use can be reduced, since heat-driven cooling consumes much less electricity than conventional compression coolers. The thermally driven absorption chiller considered in this study is driven on low-grade heat such as the waste water heat from the sugar mill. The temperature of the heat source can be as low as $75^{\circ} \mathrm{C}$ and a cooling of $6{ }^{\circ} \mathrm{C}$ is produced [8]. A cooling effect is created when heat is absorbed during the evaporation of a refrigerant at low pressure in the absorption cooling cycle. The refrigerant vapor produced is then absorbed by an absorbent and the liquid solution formed is pumped to the generator in the cycle where heat is supplied and where the refrigerant is separated from the absorbent due to evaporation at high pressure. The refrigerant vapor then goes to a condenser where heat is rejected and the absorbent continues to the absorber and the cycle repeats.

Figure 3 illustrates the overall concept of this option. In order to determine the amount of waste heat available, wastewater flows of the sugar mill were traced and calculated from available data. Wastewater flows from boiler blow down, filter mud wash and floor washing were not considered in the calculation. The waste water flows considered in the previous work [8] are from juice heaters, evaporators and crystallizers. The temperature of the wastewater which is $96{ }^{\circ} \mathrm{C}$ is amenable for absorption cooling. The procedure for the calculation of the total amount of excess wastewater flow is similar to the case of Option 1. 


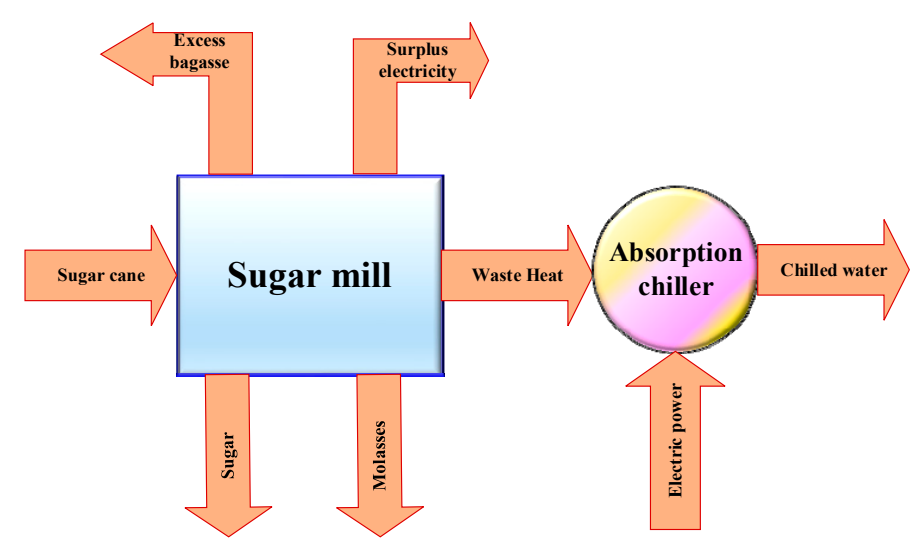

Figure 3. Sugar mill waste heat for thermally driven cooling.

\subsubsection{Option 3: Utilization of Excess Bagasse for Pellet}

Similar to any biomass, bagasse has a bulky nature which makes its handling and transportation a bit difficult. A more compact form of the bagasse in the form of pellets have the advantage of improving its handling and transportation [14]. In addition, bagasse pellets can be stored for utilization during the off-season. The fact that bagasse pellets have a much lower moisture content than the raw bagasse improves combustion in the boiler. The bagasse pelletization process basically involve drying, milling, conditioning and cooling. The heat needed for drying before pelletization of the bagasse is assumed to be obtained from flue gas heat recovery and the optimum particle size is recommended to be less than $3 \mathrm{~mm}$ [15]. More information on the pelletization principle can be found on $[9,15]$. The idea here is to pelletize excess bagasse for sale to various customers. Figure 4 illustrates the concept behind this option.

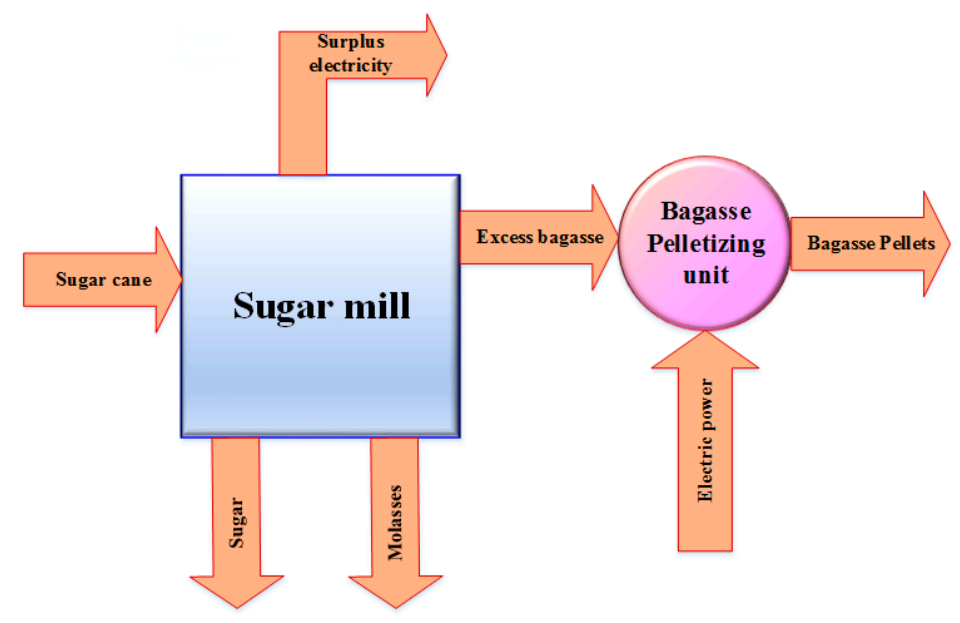

Figure 4. Utilization of excess bagasse for pellets.

\subsubsection{Option 4: Modification of the Cogeneration Unit for Maximum Electric Power Generation}

The aim of this option is to maximize electric power generation via dried bagasse and installation of a condensing extraction steam turbine (CEST). The bagasse drying results in reduced moisture content $(\mathrm{MC})$ of the bagasse which in turn leads to improved heating value. This improves the combustion temperature and boiler efficiency. As the final exhaust steam pressure from CEST is below atmospheric, the expansion of live steam down to this pressure will generate more power than if the same amount of live steam with the same conditions were expanded in a back-pressure turbine. In addition, in the case where there is excess bagasse available for use during off-season, the 
CEST will enable year round generation of electricity for sales to the grid regardless of the absence of sugar/ethanol production. Figure 5 illustrates the concept behind the technological improvement 4 .

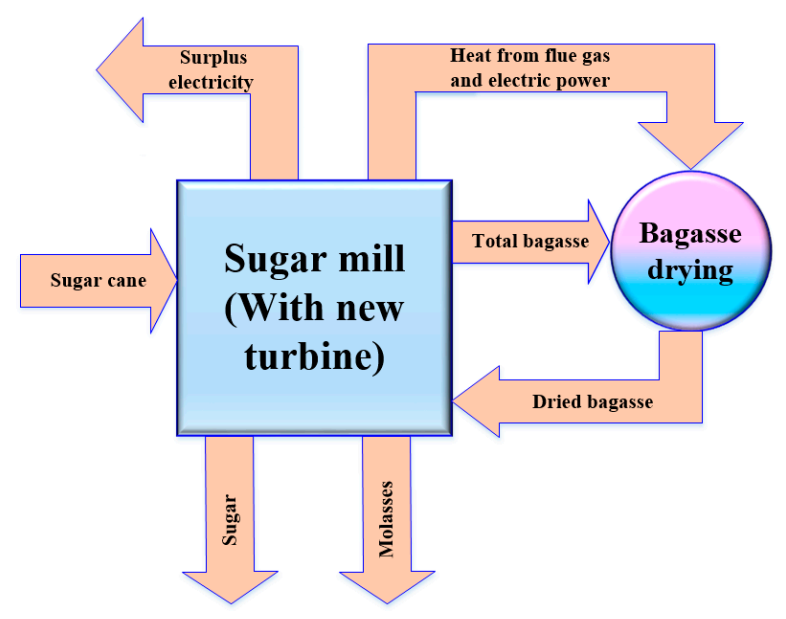

Figure 5. Maximum electric power generation using bagasse drying and new turbine setup.

\subsection{Wastewater Treatment}

As sugar mills generally produce a significant amount of wastewater, the treatment of this in a well-functioning wastewater treatment system is necessary both from environmental point of view as well as the re-use of the treated water for different activities such as irrigation and factory cleaning. The most common wastewater treatment methods include: up flow anaerobic sludge blanket (UASB) reactors, waste stabilization pond system and aerated lagoons. The existing wastewater management system at Carlos Baliño sugar mill is out of function and thus implementing proper wastewater treatment is crucial. Abdulhadi and Larsson [7] have proposed a wastewater management system for Carlos Baliño that consists of two unaerated ponds, each with facultative and maturation ponds. This wastewater treatment measure can also be applied to the other technological improvements as well and needs further investigation. Referring to the technological improvement where thermally driven cooling is considered, there are two main issues related to the contaminants in the wastewater highlighted by Feychting and Vitez [8]. The first one is that the wastewater contains some amount of sugar and this necessitates the continual cleaning of the generator unit of the absorption chilling system. The second issue is that there is a possible contamination of the wastewater by for example metallic residues from the absorption chiller. As there will be a need to re-use the wastewater after the absorption chiller for cleaning and irrigation purposes, treatment of the wastewater becomes inevitable.

Abdulhadi and Larsson [7] had collected and partly measured wastewater parameters of the Carlos Baliño sugar mill. The data can be found in Appendix $\mathrm{N}$ in [7]. The average measured values are acidity (pH): 6.4, temperature: $33.7^{\circ} \mathrm{C}$ and electric conductivity (EC): 1.05-1.08. The Biological Oxygen Demand $\left(\mathrm{BOD}_{5}\right)$ data obtained from the sugar mill lies in the range 38.5-2750. The collected data from the sugar mill has shown some variation from the measured values due to improper functioning of the lagoon 2 and also some variation of the wastewater quality during different months. Such fluctuations in the characteristics of the wastewater during different periods the year will negatively affect activities like irrigation. For instance the $\mathrm{pH}$ of the wastewater should not be below 6.2 for the proper functioning of anaerobic bacteria and their survival. As per the measurement, the EC indicates the wastewater has average salinity which makes it suitable for irrigation; however, as per the collected data the EC lies between 2.09 and 3.28 showing a big difference from the measured data and that the salinity is unstable. This shows that the wastewater cannot be guaranteed for use for irrigation purposes due to its dehydration effect on young crops given its occasional high salinity. This high salinity of the wastewater calls for the use of additional water supply for lowering the salinity. As Carlos Baliño sugar mill produces organic sugar, there are water quality standards that need to be 
followed during the process in order to meet both environmental conservation as well as the organic sugar production process requirements. The wastewater generated from organic sugar production has relatively lower content of pollutants than that generated from non-organic sugar production. Thus, such wastewater need not be wasted and reutilizing it for some activities should be considered.

\subsection{Mass and Energy Balance Relations}

Unplanned stoppages are often experienced at the Carlos Baliño sugar mill [7] and there is a variation in the seasonal value of the cane crushed. Thus, it is obvious that operation of the sugar mill at nominal parameters is not always the case. The actual operational parameters vary throughout the crushing season due to unexpected interruptions during the operation of the sugar mill [13]. This leads to variation of collected data in different crushing season and this is experienced during the in-field study conducted in different years resulting some difference in the actual operation data collected from the Baliño [7-10]. On the other hand, an actual operation parameter is more interesting for a certain analysis than a nominal value, so the analysis involves using actual operation parameters.

The base case plant data are shown in Table 1.

Table 1. Selected operation parameters for base case plant [10].

\begin{tabular}{cccc}
\hline Parameter & Value & Unit & Reference \\
\hline$M C$ & 50 & $\%$ & {$[10]$} \\
$L H V_{\text {tot, } 50 \% M C}$ & 7960 & $\mathrm{~kJ} / \mathrm{kg}$ & {$[10]$} \\
$\dot{m}_{\mathrm{b}, \text { tot }}$ & 4.25 & $\mathrm{~kg} / \mathrm{s}$ & {$[10]$} \\
$\dot{m}_{\mathrm{b}, \mathrm{ex}}$ & 0.85 & $\mathrm{~kg} / \mathrm{s}$ & {$[10]$} \\
$\mathrm{SGI}$ & 2.2 & & {$[10]$} \\
$h_{\mathrm{TEX}}$ & 2726 & $\mathrm{~kJ} / \mathrm{kg}$ & {$[10]$} \\
$h_{\mathrm{ps}}$ & 293 & $\mathrm{~kJ} / \mathrm{kg}$ & {$[10]$} \\
$h_{\mathrm{SH}}$ & 3053 & $\mathrm{~kJ} / \mathrm{kg}$ & {$[10]$} \\
$\dot{P}_{\mathrm{el}, \mathrm{BC}}$ & $2.8 \mathrm{a}$ & $\mathrm{MW}$ & {$[10]$} \\
$\dot{m}_{\mathrm{wW}, \mathrm{ex}}$ & 10 & $\mathrm{~kg} / \mathrm{s}$ & {$[7,8]$} \\
$T_{\mathrm{ww}, \mathrm{ex}}$ & 96 & ${ }^{\circ} \mathrm{C}$ & {$[7,8]$} \\
$T_{\mathrm{imb}}$ & 70 & ${ }^{\circ} \mathrm{C}$ & {$[7,8]$} \\
\hline
\end{tabular}

a $2 \mathrm{MW}$ is for in-house consumption and $0.8 \mathrm{MW}$ is sold to the grid.

Table 2 summarizes the equations used for calculating some parameters for the different technological options.

Table 2. Equations used for mass and energy balance related calculations.

\begin{tabular}{|c|c|c|}
\hline Parameter & Equation & Unit \\
\hline Net bagasse flow & $\dot{m}_{\mathrm{b}, \text { net }}=\dot{m}_{\mathrm{b}, \text { tot }}-\dot{m}_{\mathrm{b}, \mathrm{ex}}$ & $\mathrm{kg} / \mathrm{s}$ \\
\hline Total steam flow & $\dot{m}_{\mathrm{st}, \text { tot }}=\mathrm{SGI} \cdot \dot{m}_{\mathrm{b}, \text { net }}$ & $\mathrm{kg} / \mathrm{s}$ \\
\hline Heat to process & $\dot{Q}_{\mathrm{ps}}=\dot{m}_{\mathrm{st}, \mathrm{tot}} \cdot\left(h_{\mathrm{TEX}}-h_{\mathrm{FW}}\right)$ & $\mathrm{kW}$ \\
\hline Electrical power output & $\dot{P}_{\mathrm{el}}=\dot{m}_{\mathrm{st}, \mathrm{tot}} \cdot\left(h_{\mathrm{SH}}-h_{\mathrm{TEX}}\right)$ & $\mathrm{kW}$ \\
\hline Lower heating value at a certain bagasse $\mathrm{MC}^{\mathrm{a}}$ & $L H V_{\text {tot }, M C}=L H V_{\mathrm{d}} \cdot(1-M C)-2443 \cdot M C$ & $\mathrm{~kJ} / \mathrm{kg}$ \\
\hline Mass flow of bagasse at a certain bagasse MC & $\dot{m}_{\mathrm{b}, M C}=\dot{m}_{\mathrm{b}, \text { tot }} \cdot \frac{(1-0.5)}{(1-M C)}$ & $\mathrm{kg} / \mathrm{s}$ \\
\hline Fuel energy to the cycle & $\dot{\mathrm{Q}}_{\mathrm{f}}=\dot{m}_{\mathrm{b}, \text { net }} \cdot L H V_{\mathrm{tot}}$ & $\mathrm{kW}$ \\
\hline Efficiency of the cycle (BC plant) & $\eta_{\mathrm{cyc}, \mathrm{BC}}=\frac{P_{\mathrm{el}}+\dot{Q}_{\mathrm{ps}}}{\dot{Q}_{\mathrm{f}}} \cdot 100$ & $\%$ \\
\hline Efficiency of the cycle for a specific technological option & $\eta_{\mathrm{cyc}, \mathrm{opt}}=\frac{P_{\mathrm{el}}+\dot{Q}_{\mathrm{ps}}+\left(\frac{\dot{E}_{\mathrm{sav}, o \mathrm{pt}}}{t_{\mathrm{opt}} \cdot 24}\right)}{\dot{Q}_{\mathrm{f}}} \cdot 100$ & $\%$ \\
\hline
\end{tabular}

${ }^{a}$ For Option 4, the dry basis LHV (Lower Heating Value) is estimated based on HHV (Higher Heating Value) provided in [10]. 
The energy saving for Options 1, 3 and 4 is calculated based on the equations provided in Table 3; for Option 2, data are taken from Feychting and Vitez [8].

Table 3. Equations used for calculating energy saving for options 1, 3 and 4 .

\begin{tabular}{ccc}
\hline Parameter & Equation & Unit \\
\hline Energy savings for Option1 & $E_{\mathrm{sav}, \mathrm{opt} 1}=\dot{m}_{\mathrm{ww}, \mathrm{imb}} \cdot c_{\mathrm{p}, \mathrm{w}} \cdot\left(T_{\mathrm{ww}, \mathrm{ex}}-T_{\mathrm{imb}}\right) \cdot t_{\mathrm{opt} 1} \cdot 24$ & $\mathrm{MWh} /$ year \\
\hline Energy savings for Option 2 & $E_{\mathrm{sav}, \mathrm{opt} 2}=140[8]$ & $\mathrm{MWh} /$ year \\
\hline Energy savings for Option 3 & $E_{\mathrm{sav}, \mathrm{opt} 3}=\dot{m}_{\mathrm{b}, \mathrm{ex}, \mathrm{prac}} \cdot L H V_{\mathrm{tot}, 50 \% \mathrm{MC}} \cdot t_{\mathrm{opt} 3} \cdot 24$ & $\mathrm{MWh} /$ year \\
\hline Energy savings for Option $4{ }^{\mathrm{a}}$ & $E_{\mathrm{sav}, \mathrm{opt} 4}=\left(\dot{m}_{\mathrm{b}, \mathrm{tot}}-\dot{m}_{\mathrm{b}, \mathrm{MC}}\right) \cdot L H V_{\mathrm{tot}, \mathrm{MC}} \cdot \mathrm{t}_{\mathrm{opt} 4} \cdot 24$ & $\mathrm{MWh} /$ year \\
\hline & ${ }^{\mathrm{a}}$ The MC (moisture content) used is $35 \%$. &
\end{tabular}

The equations used for calculating key the economic parameters used in the analysis of this study are provided in Table 4 . The electricity price is varied from 0.25 to $0.34 \mathrm{USD} / \mathrm{kWh}$ to see its influence on the financial gain and DPBP (discounted payback period).

Table 4. Summary of equations used for calculations related to economic parameters.

\begin{tabular}{|c|c|c|}
\hline Parameter & Equation & Unit \\
\hline Cost of capital ${ }^{\text {a }}$ & $C_{\text {capital }}=\left(R e v_{\text {opt }}-C_{\text {m\&o }}\right) \cdot \frac{1-(1+r)^{-n}}{r}-I_{\text {tot }}[8,9]$ & USD/year \\
\hline Yearly net profit ${ }^{b}$ & Profit $_{\text {yearly }}=R e v_{\mathrm{opt}}-C_{\mathrm{m} \& \mathrm{o}}$ & USD/year \\
\hline \multicolumn{3}{|c|}{$\begin{array}{l}\text { Maintenance and operation } \\
\text { cost for option } 1{ }^{c}\end{array}$} \\
\hline -Maintenance cost ${ }^{\mathrm{c}}$ & $C_{\mathrm{m}, \mathrm{opt} 1}=0.1 \cdot I_{\mathrm{tot}, \mathrm{opt} 1}$ & USD/year \\
\hline -Energy price ${ }^{\mathrm{d}}$ & $E_{\text {price,opt1 }}=\frac{\tilde{\mathrm{V}}_{\mathrm{imb}, \mathrm{w}} \cdot H \cdot \rho_{\mathrm{w}} \cdot g \cdot \lambda_{\mathrm{el}} \cdot t_{\mathrm{opt} 2} \cdot 24}{3.6 \cdot 10^{6} \cdot \eta_{\mathrm{p}} \cdot \eta_{\mathrm{m}}}$ & USD/year \\
\hline
\end{tabular}

\footnotetext{
${ }^{a}$ By setting the cost of capital to zero and solving for $n$, the discounted payback period (DPBP) is estimated;

${ }^{b}$ This is the same as the financial gain for Options $1-4 ;{ }^{c}$ The labour cost is negligible. The maintenance cost is assumed to be $10 \%$ per year of the initial investment cost [16]; $\mathrm{d}$ The volume flowrate is estimated about $22.5 \mathrm{~m}^{3} / \mathrm{h}$ based on the additional $6 \mathrm{~kg} / \mathrm{s}$ imbibition water [7]. The water is assumed to be under a $3 \mathrm{~m}$ head [17] and the density taken at $96^{\circ} \mathrm{C}$. The pump and electric motor efficiencies are assumed to be $90 \%$ each. The acceleration due to gravity is $9.81 \mathrm{~m} / \mathrm{s}^{2}$.
}

\section{Results}

In this section, the comparison results for the four technological options are presented.

\subsection{Summary of Key Results from the Four Technological Options}

\subsubsection{Option 1}

Table 5 provides some of the main results for Option 1 . The excess wastewater flow was calculated to be $10 \mathrm{~kg} / \mathrm{s}$ with a temperature of $96^{\circ} \mathrm{C}$. In the study by Abdulhadi and Larsson [7], the wastewater was considered to be partly utilized for imbibition and partially available for a wastewater management system which will be generating treated water for irrigation. The crushing season was considered to be 140 days per year. The amount of the optimized imbibition water was estimated as $11 \mathrm{~kg} / \mathrm{s}$ whereas the base case imbibition water flow was calculated to be $5.6 \mathrm{~kg} / \mathrm{s}$. The amount of wastewater remaining for wastewater management system was estimated to be $4 \mathrm{~kg} / \mathrm{s}$. The total sugar production after the optimized imbibition water flow is used is estimated to be $2.5 \mathrm{~kg} / \mathrm{s}$ which is an $8.7 \%$ increase from the base case sugar production. The model result of the study indicated that there will be a net financial gain of USD 1.4 million due to the optimized imbibition flow and thus increased sugar production. 
Table 5. Results for Option 1.

\begin{tabular}{|c|c|c|c|}
\hline Parameter & Value & Unit & Reference \\
\hline Part of excess wastewater reused for imbibition, $\dot{m}_{\mathrm{ww}, \mathrm{imb}}$ & 6 & $\mathrm{~kg} / \mathrm{s}$ & [7] \\
\hline Optimized imbibition water flow, $\dot{\boldsymbol{m}}_{\text {optim,imb }}$ & 11 & $\mathrm{~kg} / \mathrm{s}$ & [7] \\
\hline Crushing season, $t_{\text {opt1 }}$ & 140 & Days & [7] \\
\hline Revenue from sugar produced, $\operatorname{Rev}_{\mathrm{s}}{ }^{\mathrm{a}}$ & 1.4 & $10^{6} \mathrm{USD} /$ year & [7] \\
\hline Investment cost, $I_{\text {opt } 1}$ b & 3500 & USD & [18] \\
\hline Maintenance and operating cost, $C_{\mathrm{m} \& \mathrm{o}}{ }^{\mathrm{c}}$ & 570 & USD/year & \\
\hline
\end{tabular}

a Calculated value and refers to the net revenue from the increased sugar production; ${ }^{\mathrm{b}}$ cost of the pump needed for the additional imbibition water; ${ }^{c}$ calculated value using equations in Table 4.

\subsubsection{Option 2}

The main results for Option 2 are summarized in Table 6. The excess water flow was calculated to be $10 \mathrm{~kg} / \mathrm{s}$ with a temperature of $96^{\circ} \mathrm{C}$. The maximum cooling demand is estimated to be $288 \mathrm{~kW}$. Energy saving per crushing season is $140,000 \mathrm{kWh}$, which corresponds to the current electricity consumption of the vapor compression units (equivalent of 40,000 USD/season). The potential revenue from excess electricity production of the base case plant is USD 800,640 per year based on an electricity price of $0.3 \mathrm{USD} / \mathrm{kWh}$ and $0.8 \mathrm{MW}$ peak export capacity. In the study for this option, the crushing season is considered to be 139 days per year. Considering the $140,000 \mathrm{kWh}$, financial savings of USD 40,000 per year with a payback of 3-6 years (depending on the type of equipment selected) were estimated.

Table 6. Results for Option 2 as taken from [8].

\begin{tabular}{|c|c|c|}
\hline Parameter & Value & Unit \\
\hline Total bagasse flow, $\dot{m}_{\mathbf{b}, \text { tot }}$ & $8.8^{\mathrm{a}}$ & $\mathrm{kg} / \mathrm{s}$ \\
\hline Energy saving per crushing season, $E_{\mathrm{sav}, \mathrm{opt} 1}$ & $140,000^{b}$ & kWh \\
\hline Crushing season, $t_{\mathrm{opt} 1}$ & 139 & Days \\
\hline Total investment cost, $\boldsymbol{I}_{\text {tot }}$ & 152,326 & USD/year \\
\hline Maintenance and operating cost, $C_{\mathrm{m} \& \mathrm{o}}$ & 1171 & USD/year \\
\hline Revenue $^{\mathrm{c}}, \boldsymbol{\operatorname { R e v }} \mathrm{v}_{\mathrm{abs}}$ & 41,490 & USD/year \\
\hline
\end{tabular}

a When estimating the excess bagasse flow, the ratio of the excess bagasse and total bagasse flow presented in Table 1 will be considered; ${ }^{\mathrm{b}}$ Corresponds to the current electricity consumption of the vapor compression units;

${ }^{\mathrm{c}}$ Due to saved electricity after installing thermally driven absorption chiller.

\subsubsection{Option 3}

Some of the main results for Option 3 as taken from [9] are summarized in Table 7. The study model results for the third technological option showed that the seasonal practical amount of excess bagasse was 11,500 t/season, whereas the seasonal nominal amount of excess bagasse was estimated to be 37,000 $\mathrm{t} /$ season. Considering the practical amount of excess bagasse, the study result indicated that 7300 ton of pellets/year can be produced. The investment cost was calculated to be USD 3.4 million and the crushing season was considered to be 125 days per year.

Table 7. Results for Option 3 as taken from [9].

\begin{tabular}{|c|c|c|}
\hline Parameter & Value & Unit \\
\hline Practical amount of excess bagasse flow, $\dot{m}_{\mathbf{b}, \mathbf{e x}, \text { prac }}$ & 11.5 & $10^{3}$ tonnes/year \\
\hline Nominal amount of excess bagasse flow, $\dot{m}_{\mathrm{b}, \mathbf{e x}, \text { nom }}$ & 37 & $10^{3}$ tonnes/year \\
\hline Yearly pellet production capacity, $\dot{m}_{\text {pellet }}$ & $7.3^{\mathrm{a}}$ & $10^{3}$ tonne/year \\
\hline Crushing season, $t_{\mathrm{opt} 3}$ & 125 & Days \\
\hline Total investment cost, $\boldsymbol{I}_{\text {tot }}$ & 1307 & $10^{3} \mathrm{USD} /$ year \\
\hline Maintenance and operating cost, $C_{\mathrm{m} \& \mathrm{o}}$ & 363 & $10^{3} \mathrm{USD} /$ year \\
\hline Revenue, $R e v_{\text {pellet }}$ & $1068^{\mathrm{a}}$ & $10^{3} \mathrm{USD} /$ year \\
\hline
\end{tabular}

${ }^{a}$ Considering the practical amount of excess bagasse. 


\subsubsection{Option 4}

This selected scenario considers the bagasse drying and installation of a condensing extraction steam turbine. Key results for Option 4 are provided in Table 8. The results from this scenario showed that the maximum surplus electrical energy reaches close to $13.4 \mathrm{GWh}$ and the investment cost for installing a new dryer and turbine is estimated to be USD 6.3 million with a payback time of 1.7 years. The yearly profit is estimated to be USD 3.7 million. The crushing season is considered to be 140 days per year.

Table 8. Results for Option 4 as taken from [10].

\begin{tabular}{ccc}
\hline Parameter & Value & Unit \\
\hline Excess power capacity, $\dot{\boldsymbol{P}}_{\mathbf{e l}, \mathbf{e x}}$ & 3.9 & $\mathrm{MW}$ \\
Crushing season, $\boldsymbol{t}_{\mathbf{o p t}}$ & 140 & Days \\
Total investment cost, $\boldsymbol{I}_{\mathbf{t o t}}$ & 5045 & $10^{3} \mathrm{USD} /$ year \\
Maintenance and operating cost, $\boldsymbol{C}_{\mathbf{m} \& \mathbf{o}}$ & 195 & $10^{3} \mathrm{USD} /$ year \\
Revenue, $\boldsymbol{R e v}_{\mathbf{e l}, \mathbf{e x}}$ & 3931 & $10^{3} \mathrm{USD} /$ year \\
\hline
\end{tabular}

\subsubsection{Comparison of the Different Technological Options}

In all four technological improvement studies, the electricity sales price was considered to be $0.3 \$ / \mathrm{kWh}$, and for detailed sensitivity analysis of the electricity price along with other parameters the reader is referred to [8-10]. As per the calculation results from this study, for Option 1, the variation of the electricity price from 0.25 to $0.34 \mathrm{USD} / \mathrm{kWh}$ does not produce a significant variation in the calculated net financial gain and DPBP. For Option 2, the net financial gain and the DPBP vary from 33,404 to 45,851 USD/year and 8 to 5 years, respectively. For Option 3, the net financial gain and the DPBP vary from 526,821 to 847,195 USD/year and 3 to 2 years, respectively. For Option 4 , the net financial gain and the DPBP vary from 3 million to 4.3 million USD/year and 2 to 1.4 years, respectively. For all the options, the discount rate was considered to be $15 \%$ as Cuba is a developing country and compared to developed countries there is lower risk in the economy [7-9].

The results of the calculated parameters based on data provided in Table 1 and using equations in Table 2 are presented in Table 9. The table also shows cycle efficiency as considered for the four options. As can be seen in the table, the efficiency of the cycle is more sensitive to the technological improvements Option 3 and 4 as compared to the other two options.

Table 9. Calculated parameters and cycle efficiency for the four options.

\begin{tabular}{|c|c|c|c|c|c|}
\hline Parameter & Unit & Option 1 & Option 2 & Option 3 & Option 4 \\
\hline Mass flow of net bagasse & $\mathrm{kg} / \mathrm{s}$ & $7.0^{\mathrm{a}}$ & $7.0^{\mathrm{a}}$ & 3.7 & 3.3 \\
\hline Total steam flow, BC is & $\mathrm{kg} / \mathrm{s}$ & $15.5^{\mathrm{b}}$ & $15.5^{\mathrm{b}}$ & $8.1^{\mathrm{b}}$ & 11.4 \\
\hline Fuel input & MW & 56.0 & 56.0 & 29.3 & $27.1^{\mathrm{c}}$ \\
\hline $\begin{array}{c}\text { Electrical power output } \\
\text { (2 MW in-house and } 0.8 \mathrm{MW} \text { is sold) }\end{array}$ & MW & 2.8 & 2.8 & 1.6 & 2.8 \\
\hline Process heat demand & MW & 37.7 & 37.7 & 19.7 & 18.2 \\
\hline Efficiency of cycle (BC), LHV basis & $\%$ & 72.2 & 72.2 & 72.8 & 77.6 \\
\hline Efficiency cycle (Options), LHV basis & $\%$ & 73.4 & 72.8 & 100.4 & 106.1 \\
\hline
\end{tabular}

Based on the input data collected from the four studies [7-10] and the calculated parameters in Table 9, two comparison charts are generated as shown in Figures 6 and 7. Figure 6 illustrates the energy savings and cycle efficiency increments of all four options. 


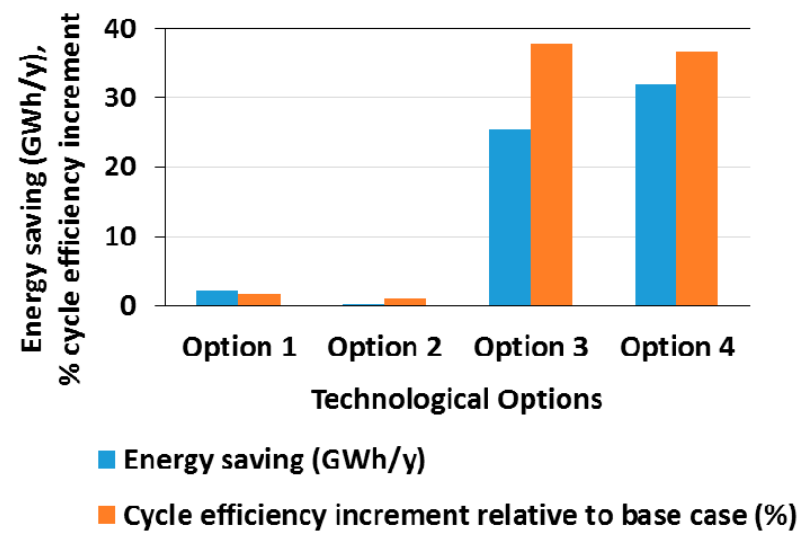

Figure 6. Energy saving and cycle efficiency increment (relative to base case) for the four options.

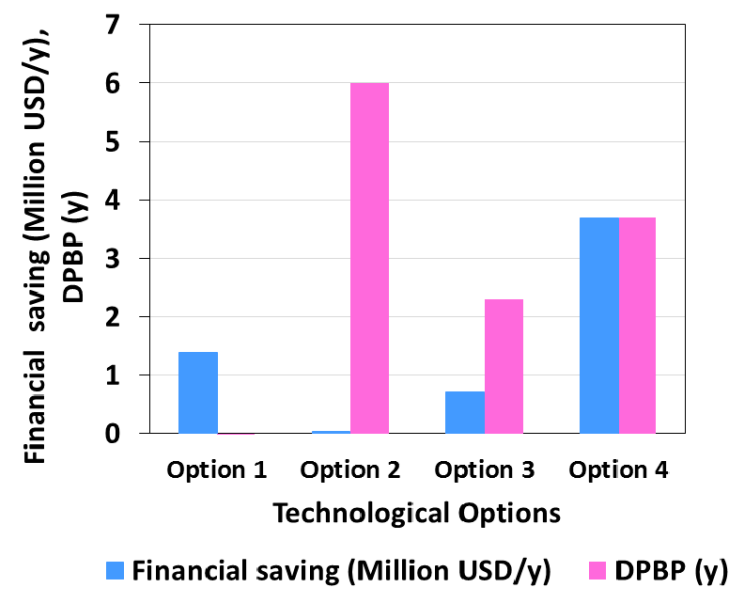

Figure 7. Financial savings and DPBP (discount payback period) for the four options.

Figure 7 illustrates the financial saving per year and the DPBP for the four options. The cycle efficiency for Options 3 and 4 are relatively higher than for the other options as surplus power generation (Option 4) and pellets (Option 3) are produced.

For options 3 and 4 , the contribution of the technological improvement to minimize emission is obvious in that the use of bagasse for power generation is a $\mathrm{CO}_{2}$-neutral alternative, whereas for Options 1 and 2, in addition to heat recovery, the reuse of part of the wastewater reduces BOD and Chemical Oxygen Demand (COD) concentrations in the river where it is disposed. In addition, for Option 2, the implementation of heat driven absorption cooling system instead of the existing vapour compression systems that are driven by fossil fuel generated electricity, the $\mathrm{CO}_{2}$ emission is calculated by considering the amount of electric power $(140,000 \mathrm{kWh})$ consumed by the existing vapour compression systems. Similarly, for Options 3 and 4 , the $\mathrm{CO}_{2}$ emission savings are calculated based on the amount of energy saved per crushing season. The amount of $\mathrm{CO}_{2}$ from fuel oil-based power generation considered in the calculation of the $\mathrm{CO}_{2}$ emission saved equals $675 \mathrm{~g} \mathrm{CO}_{2} / \mathrm{kWh}$ [19]. Figure 8 illustrates the $\mathrm{CO}_{2}$ emissions saved in tonnes/year and the cost of $\mathrm{CO}_{2}$ reduction per tonne of $\mathrm{CO}_{2}$ for Options 2-4. The $\mathrm{CO}_{2}$ emissions associated with Option 1 are unaffected by the technological improvement made; however, the sugar yield increases. Option 3 represents the most cost-effective $\mathrm{CO}_{2}$ reduction technology, although its level is much higher than benchmarks like the EU Emissions Trading Scheme [20].

As can be seen from Figures 6 and 8 , the amount of $\mathrm{CO}_{2}$ emission saved corresponds to the amount of energy saved for the respective options. The $\mathrm{CO}_{2}$ emissions saved for Option 2 is quite small as compared to the emissions saved from the other options and are estimated to be 94.5 tonnes/year. 


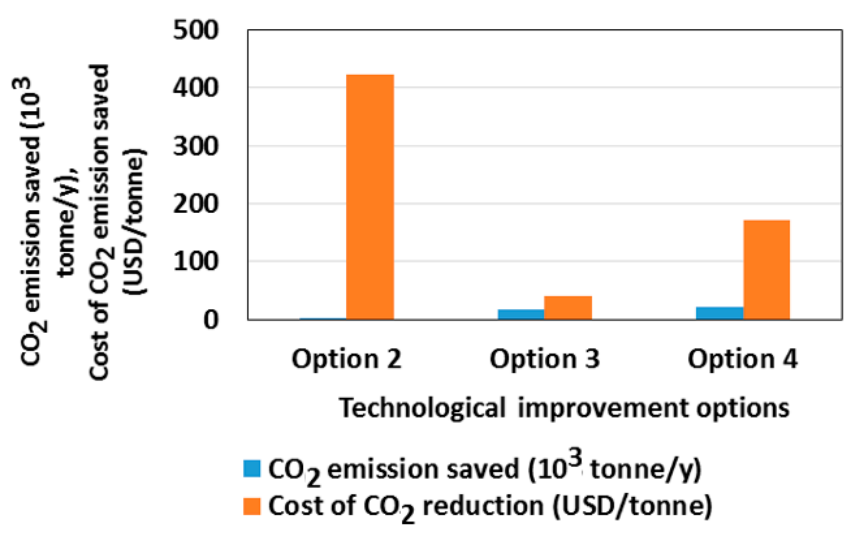

Figure 8. Amount of $\mathrm{CO}_{2}$ emission saved and cost of $\mathrm{CO}_{2}$ reduction per tonne $\mathrm{CO}_{2}$ for Options 2-4.

The choice of which technological option should be prioritized depends on its relevance to the current Carlos Baliño sugar mill situation. The advantage with implementing Option 3 and Option 4 together can be that taking into account the seasonality of sugar production, the pellets can be saved for off-season and can either be sold or used for power generation by the sugar mill during off-season. In addition, during unexpected interruptions, the pellets can be used as a back-up fuel. Considering Option 2, though the cycle efficiency is not affected much by the re-use of the waste heat in the wastewater for absorption cooling technology. However, the implementation of Option 2 is a viable technology and worth investment if the priority of Carlos Baliño sugar mill is to have a cooling supply which is based on a renewable energy resource. On the other hand, Option 2 is reliable only for the crushing season and so does not guarantee a cooling supply during off-season.

\section{Conclusions}

The purpose of this study was to compare the four technological options that were proposed for the Carlos Baliño sugar mill and suggest which option is suitable to implement. For this, different factors are considered as comparison parameters, and the implementation of technological improvements 3 and 4 have more sensitivity to the improvement of the cycle efficiency. The cycle efficiencies calculated for Option 3 and Option 4 are 37.9\% and 36.8\%, respectively. This alone, however, does not necessarily lead to the conclusion that these options need to be prioritized compared to Option 1 and Option 2. Option 2 can be attractive, if an improved and environmentally friendly air conditioning system for the factory is prioritized regardless of the longer DPBP compared to the other options. The prioritizing of the four options was examined from other points of views as well: financial gains, DPBP and energy saving. The $\mathrm{CO}_{2}$ emissions saved due to Option 4 are the highest (21,538 tonnes/year) and for Option 2 it is the lowest (94.5 tonnes/year). The cost of $\mathrm{CO}_{2}$ emissions saved for Options 2 (highest) and 3 (lowest) is estimated to be 423 and $41 \mathrm{USD} /$ tonne of $\mathrm{CO}_{2}$ emissions saved, respectively.

Acknowledgments: Many thanks for the financial support of the Swedish International Development Cooperation Agency (SIDA) that funds this project. Thanks to all from Carlos Baliño sugar mill staff for providing data and necessary information during the field study. Our thanks to the scholarship providers from SIDA's Minor Field Studies (MFS) in developing countries programme and Din Els Miljöfond, which funded the field trips to Cuba. Publishing costs were assumed by KTH, Division of Heat and Power Technology.

Author Contributions: E. Birru has substantially contributed to the writing of the manuscript, the analysis regarding the comparison of the technological options considered in this study and to the interpretation of results. C. Erlich and A. Martin have contributed to the design of the study and to the preparation of the manuscript. I. Herrera provided data from Carlos Baliño sugar mill. The remaining authors have contributed via BSc thesis work: B. E. Abdulhadi and A. Larsson (Option 1 study); S. Feychting and F Vitez (Option 2 study); E. Onoszko and M. Hallerbo (Option 3 study); and L. Weilenmann and L. Puskoriute (Option 4 study).

Conflicts of Interest: The authors declare no conflict of interest. The funding sponsors had no role in the design of the study; in the collection, analyses, or interpretation of data; in the writing of the manuscript, and in the decision to publish the results. 


\section{Nomenclature}

\begin{tabular}{lll} 
Character & Parameter & Unit \\
$\dot{m}$ & Mass flow & $\mathrm{kg} / \mathrm{s}$ \\
$\dot{Q}$ & Heat flow & $\mathrm{kW}$ or $\mathrm{MW}$ \\
$\dot{P}$ & Power & $\mathrm{kW}$ or $\mathrm{MW}$ \\
$\eta$ & Efficiency & $\%$ \\
$h$ & Enthalpy & $\mathrm{kJ} / \mathrm{kg}$ \\
$E$ & Energy & $\mathrm{GWh}$ \\
$c_{p}$ & Specific heat capacity & $\mathrm{kJ} / \mathrm{kg} \cdot{ }^{\circ} \mathrm{C}$ \\
$C$ & Cost & $\mathrm{USD} / \mathrm{year}$ \\
$n$ & Period & $\mathrm{years}$ \\
$r$ & Discount rate & $\%$ \\
$I$ & Investment & $\mathrm{USD}$ \\
$G$ & Financial gain & $\mathrm{USD} / \mathrm{year}$ \\
$R e v$ & Revenue & $\mathrm{USD} / \mathrm{year}$ \\
$t$ & Crushing season & $\mathrm{days}$ \\
$\tilde{V}$ & Volume flow & $\mathrm{m}{ }^{3} / \mathrm{h}$ \\
$\lambda$ & Electricity price & $\mathrm{USD} / \mathrm{kWh}$ \\
$\rho$ & Density & $\mathrm{kg} / \mathrm{m}{ }^{3}$ \\
$g$ & Standard gravity & $\mathrm{m} / \mathrm{s}^{2}$ \\
$H$ & head & $\mathrm{m}$ \\
\hline
\end{tabular}

\section{Superscripts}

\begin{tabular}{ll} 
b & Bagasse \\
BC & Base Case plant \\
ex & Excess \\
el & Electricity \\
$\mathrm{f}$ & Fuel \\
net & Net mass flow \\
$\mathrm{m}$ & Maintenance \\
opt & Option \\
ps & Process \\
st & Steam \\
SH & Superheated \\
Tot & Total \\
Tex & Turbine exhaust \\
FW & Feed water \\
d & Dry basis \\
Optim & Optimum \\
Cyc & Cycle \\
sav & Saving \\
ww & Wastewater \\
imb & imbibition \\
nom & nominal \\
w & water \\
prac & practical \\
m\&o & Operation and maintenance \\
s & sugar \\
$\mathrm{m}$ & maintenance \\
abs & absorption chiller \\
\hline &
\end{tabular}




$\begin{array}{ll}\text { Abbreviations } & \\ \text { CEST } & \text { Condensing extraction steam turbine } \\ \text { MC } & \text { Moisture content } \\ \text { BOD } & \text { Biological Oxygen Demand } \\ \text { DPBP } & \text { Discounted Payback Period } \\ \text { TCD } & \text { Tonne of cane per day } \\ \text { COD } & \text { Chemical Oxygen Demand } \\ \text { SGI } & \text { Steam Generation Index } \\ \text { LHV } & \text { Lower Heating Value } \\ \text { HHV } & \text { Higher Heating Value }\end{array}$

\section{References}

1. IEA (International Energy Agency). Water for Energy, Is Energy Becoming a Thirstier Resource? 2012. World Energy Outlook. Available online: http://www.worldenergyoutlook.org/media/weowebsite/2012/WEO_ 2012_Water_Excerpt.pdf (accessed on 15 February 2016).

2. Brazilian Sugarcane Industry Association (UNICA). Sugarcane, One Plant, Many Solutions. Sugar, Ethanol, Bioelectricity \& Beyond, 2013. Available online: http://sugarcane.org/resource-library/books/Folder\% 20and\%20Brochure.pdf (accessed on 15 February 2016).

3. World Alliance for Decentralized Energy (WADE). Bagasse Cogeneration Global Review and Potential. 2004. Available online: https://cdm.unfccc.int/filestorage/2/K/J/2KJXDVUHFZ0MYG3WOBT91NA7QE6LP5/ 4057\%20Annex\%206\%20Bagasse\%20Cogeneration\%20-\%20Global\%20Review\%20and\%20Potential.pdf? $\mathrm{t}=$ VEZ8b2gyam16fDBg_sTaUEyZyK4ZfHSdBYCe (accessed on 7 March 2016).

4. Kamate, C.S.; Gangavati, B.P. Cogeneration in sugar industries: Technology options and performance parameters-A review. Cogener. Distrib. Gener. J. 2009, 24, 6-33. [CrossRef]

5. Deshmukh, R.; Jacobson, A.; Chamberlin, C.; Kammen, C. Thermal gasification or direct combustion? Comparison of advanced cogeneration systems in the sugarcane industry. Biomass Bioenergy 2013, 55, 163-164. [CrossRef]

6. Carpio, C. Energy Efficiency in Latin America and the Caribbean: Situation and Outlook; United Nations: Santiago, Chile, 2010. Available online: http://www.cepal.org/publicaciones/xml/2/39412/lcw280i.pdf (accessed on 3 May 2016).

7. Abdulhadi, B.E.; Larsson, A. Alternative Utilization of Excess Water in Cuban Sugar Mills. Bachelor's Thesis, KTH Royal Institute of Technology, Stockholm, Sweden, 2014. Available online: http:/ /www.diva-portal. org/smash/record.jsf?pid=diva2\%3A735263\&dswid=818 (accessed on 21 January 2016).

8. Feychting, S.; Vitez, F. Utilization of Waste Heat from Sugar Mills in Cuba for Thermally Driven Cooling. Bachelor's Thesis, KTH Royal Institute of Technology, Stockholm, Sweden, 2014. Available online: http: / /www.diva-portal.org/smash/record.jsf?pid=diva2\%3A735241\&dswid=-9590 (accessed on 21 January 2016).

9. Onoszko, E.; Hallersbo, M. An Investigation of New Markets for the Bagasse in Cuban Sugar Mills. Bachelor's Thesis, KTH Royal Institute of Technology, Stockholm, Sweden, 2015. Available online: http:/ /www.divaportal.org/smash/get/diva2:840907/FULLTEXT01.pdf (accessed on 21 January 2016).

10. Nylund, L.; Puskoriute, L. Cogeneration Unit Modifications to Maximize the Electricity Generation in Cuban Sugar Mill. Bachelor's Thesis, KTH Royal Institute of Technology, Stockholm, Sweden, 2015. Available online: http:/ / www.diva-portal.se/smash/get/diva2:840913/FULLTEXT01.pdf (accessed on 21 January 2016).

11. United Nations. Trading Opportunities for Organic Food Products from Developing Countries; United Nations: New York, NY, USA; Geneva, Switzerland, 2004. Available online: http://unctad.org/en/ PublicationsLibrary/ditcted11d.pdf (accessed on 10 August 2016).

12. Alba, D.S. Evaluación de Alternativas de Cogeneración en la UEB Central Carlos Baliño. Trabajo de Diploma, Universidad Central "Marta Abreu" De Las Villas, Facultad de Ingeniería Mecánica Centro de Estudios Energéticos y de Tecnologías Ambientales, Santa Clara, Cuba, 2014.

13. Birru, E.; Erlich, C.; Beyene, G.B.; Martin, A. Assessing the potential of energy saving in a traditional sugar cane mill during steady state and transient conditions-Part I: Base case plant model. Biomass Conv. Biorefin. 2015, 6, 219-232. [CrossRef]

14. Erlich, C.; Öhman, M.; Björnbom, E.; Fransson, H.T. Thermochemical characteristics of sugar cane bagasse pellets. Fuel 2005, 84, 569-575. [CrossRef] 
15. Erlich, C. Comparative Study of Residue Pellets from Cane Sugar and Palm-Oil Industries with Commercial Wood Pellets, Applied in Downdraft Gasification. Ph.D. Thesis, Department of Energy Technology, KTH Royal Institute of Technology, Stockholm, Sweden, 2009. Available online: https:/ /www.diva-portal.org/ smash/get/diva2:272453/FULLTEXT01.pdf (accessed on 22 August 2016).

16. Hydraulic Institute; Europump; The US Department of Energy's Office of Industrial Technologies (OIT). Pump Life Cycle Costs: A Guide to LCC Analysis for Pumping Systems, Executive Summary. 2001. Available online: https://www1.eere.energy.gov/manufacturing/tech_assistance/pdfs/pumplcc_1001.pdf (accessed on 22 August 2016).

17. Hugot, E. Handbook of Sugar Cane Engineering, 3rd ed.; Elsevier: New York, NY, USA, 1986; p. 244.

18. Alibaba-Energy Saving Siemens Electric Water Pump. Available online: https://www.alibaba.com/productdetail/Energy-saving-siemens-electric-water-pump_60317318094.html?spm=a2700.7724857.0.0.G64Mbp (accessed on 22 August 2016).

19. International Energy Agency (IEA). $\mathrm{CO}_{2}$ Emissions from Fuel Combustion-Highlights. 2015. Available online: https://www.iea.org/publications/freepublications/publication/CO2EmissionsFromFuelCombustion Highlights2015.pdf (accessed on 27 April 2016).

20. Carbon Trust. Cutting Carbon in Europe. The 2020 plans and the future of the EU ETS. 2008. Available online: https:/ / www.carbontrust.com/media/84896/ctc734-cutting-carbon-in-europe-2020-plans.pdf (accessed on 23 November 2016).

(C) 2016 by the authors; licensee MDPI, Basel, Switzerland. This article is an open access article distributed under the terms and conditions of the Creative Commons Attribution (CC-BY) license (http://creativecommons.org/licenses/by/4.0/). 